\title{
Correction to: Comprehension of Idioms by Jordanian Arabic-Speaking Children
}

\author{
Jihad M. Hamdan ${ }^{1} \cdot$ Alaa' M. Smadi $^{2}$ \\ Published online: 10 March 2021 \\ (c) Springer Science+Business Media, LLC, part of Springer Nature 2021
}

\section{Correction to: Journal of Psycholinguistic Research https://doi.org/10.1007/s10936-021-09773-4}

The original version of the article has contained a mistakes in Tables 2 and 6.

The corrected Tables 2 and 6 are given below.

The original article has been corrected.

The original article can be found online at https://doi.org/10.1007/s10936-021-09773-4.

Alaa' M. Smadi

alsmadi_alaa88@yahoo.com

Jihad M. Hamdan

jihaddan@yahoo.com

1 Department of English Language and Literature, Zarqa University, Zarqa, Jordan

2 Department of Basic Sciences, Al-Balqa Applied University, Salt, Jordan 


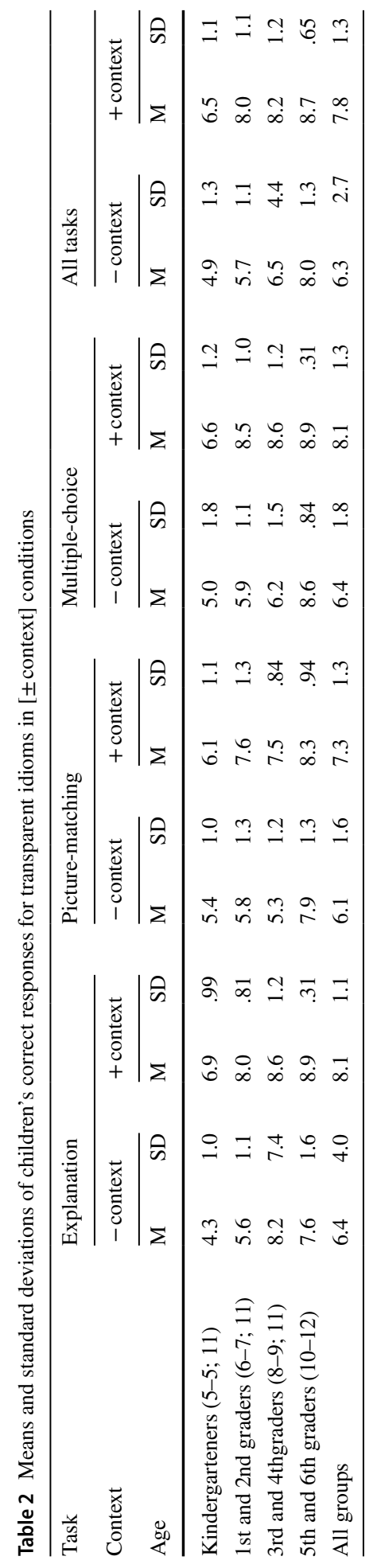




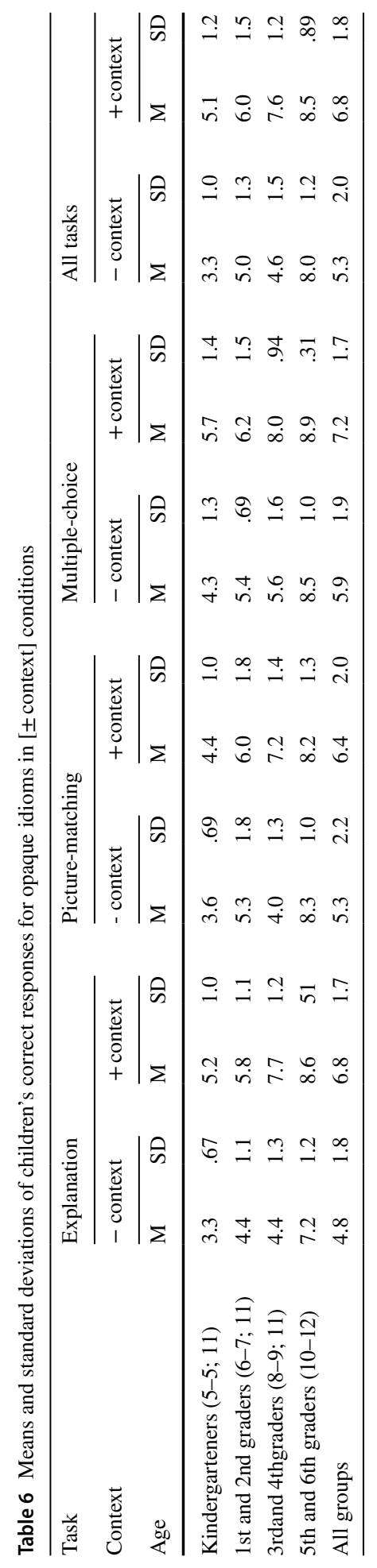


Publisher's note Springer Nature remains neutral with regard to jurisdictional claims in published maps and institutional affiliations. 